\title{
Processo de inclusão digital em rede empresarial do segmento de suprimentos industriais: utilização de tecnologias de informação e comunicação
}

Sonia Cruz-Riascos de Andrade

Consultora em inteligência empresarial. Mestre em ciência da informação pela Universidade de Brasília (UnB). Especialista em inteligência organizacional e competitiva pela $\mathrm{UnB}$.

E-mail: sonia.cruzriascos@gmail.com

\section{Resumo}

Apresenta resultados de estudo realizado com 17 empresas de representação comercial do segmento de suprimentos industriais de produtos técnicos de borracha. Foram aplicados questionários e os resultados delinearam o modus operandi das empresas quanto à gestão da informação considerando infra-estrutura tecnológica e utilização de tecnologias de informação e comunicação. Aborda questões como gestão da informação para a tomada de decisão, redes de informação em pequenas e médias empresas, gestão do conhecimento e educação corporativa. Finaliza com ferramentas tecnológicas que apóiam o ensino-aprendizagem e sugere a inclusão empresarial como alternativa de capacitação para o desenvolvimento e promoção da cidadania na nova sociedade da informação e do conhecimento.

\section{Palavras-chave}

Inclusão digital. Inclusão empresarial. Gestão do conhecimento. Tecnologias de informação e comunicação. Empresa de representação comercial de base industrial.

\section{Digital inclusion process in a network of industrial suppliers enterprises: the use of information and communication technologies}

\begin{abstract}
This paper presents results of a study carried out with 17 representative enterprises of industrial supplies (specifically tire rubber). The research data were collected via questionnaires. Results showed that the modus operandi within the enterprises environment is related to information management. The technological infrastructure in terms of information and communication technologies (ICT) has been taken into account in the study. The paper approaches a number of topics, namely, information management for decision making, information network on the basis of a common pool of small and medium enterprises support, knowledge management and corporative education. Finally, technological tools to enhance teaching and learning processes are discussed. The main suggestion of the study is that the enterprises inclusion as an option to institutional capacity-building is needed, in order to foster constructive change in this new knowledge and information society.
\end{abstract}

\section{Keywords}

Digital inclusion. Enterprises inclusion. Knowledge management. Information and communication technologies. Representative enterprises of industrial suppliers. 


\section{INTRODUÇÃO}

O estudo vem consolidando, no decorrer dos últimos três anos, uma linha de desenvolvimento baseada no potencial de pequenas e médias empresas de representação comercial detentoras de bens intangíveis. No Brasil, trata-se de um segmento com capilaridade em nível nacional que pode atuar em prol do desenvolvimento local, após atingir um grau de competência em informação.

Este artigo contempla a inclusão digital no segmento das pequenas e médias empresas de representação comercial que atuam na área de suprimentos industriais, especificamente com produtos técnicos de borracha. Como a própria denominação sugere, empresas de representação comercial "representam" os interesses comerciais de grandes empresas e de multinacionais. Isso implica dizer que tais organizações precisam apresentar um diferencial significativo quanto ao bem intangível "conhecimento", de forma que possam entender e manejar negócios de caráter essencialmente técnico. Para tanto, a formação de redes para o compartilhamento de dados, informações e conhecimento na área industrial se faz requisito.

Trata-se de um segmento pouco explorado pela literatura em razão do nível de especialização da área. As necessidades informacionais requeridas para o desenvolvimento deste tipo de negócio são específicas em função do ramo de atividade econômica, do próprio porte da empresa e da sua localização geográfica.

Em geral, são empresas de pequeno ou médio porte, com estrutura enxuta, que não podem contar com quantidade ideal de funcionários, por causa dos encargos salariais. Normalmente, incide alta taxação de impostos, requerendo restrições orçamentárias. Tais características, por vezes, inviabilizam o crescimento empresarial. Com base nas dificuldades apresentadas, levantam-se as seguintes questões: Como investir em recursos tecnológicos? Como agregar valor aos serviços para atrair seus clientes? Como interagir de forma mais efetiva com suas representadas? Como socializar a informação nesta rede? Ou seja, como a inclusão digital pode contribuir para promover o desenvolvimento destas empresas, visando à geração do conhecimento como base para o crescimento empresarial?

Destacam-se os seguintes fatores que dificultam o segmento estudado: geralmente, o local se encontra isolado geograficamente e afastado dos principais canais de informação, dificultando a disponibilidade de recursos humanos capacitados, além do acesso ao conhecimento e à informação especializada - requisitos fundamentais para impulsionar o desenvolvimento. Somando-se a isso, tem-se o fato de que muitas empresas ainda focalizam o "equipamento" como solução para o crescimento empresarial. No artigo, evidencia-se que ele é necessário, porém restringe-se a servir como mero instrumento para compartilhar conteúdos. Estes, sim, é que podem potencializar as ações empresariais, merecendo, portanto, um tratamento especializado.

O estudo teve como propósito ressaltar os impactos causados pelos avanços tecnológicos nestas pequenas e médias empresas, averiguar a participação de sócios e funcionários em cursos a distância e treinamentos, além de contribuir com orientações para melhorias dos processos informacionais, destacando a mediação da informação e o compartilhamento do conhecimento entre os atores envolvidos nesta rede empresarial.

objetivo foi identificar ações que pudessem fortalecer o processo de inclusão digital para favorecer a geração de conhecimentos específicos entre os componentes da rede, mediante o fluxo de informações estratégicas, tecnológicas, mercadológicas, comerciais e sociais. Neste sentido, era preciso apresentar uma visão geral acerca do perfil das referidas empresas no que tange à área de informação e comunicação.

Quanto aos procedimentos metodológicos, foi realizada a análise de literatura e observou-se que praticamente inexistem informações sobre o foco deste estudo. Partiuse, então, para o levantamento de artigos sobre áreas correlatas.

Procurou-se identificar empresas de representação comercial que atuam no mesmo nicho técnico-industrial e optou-se pelo segmento de suprimentos industriais, especificamente, produtos técnicos de borracha. A amostra contemplou 17 empresas localizadas em diversos estados do país, interligadas, por representarem uma empresa multinacional em comum. A maior parte destas empresas é responsável por mais de um estado e, juntas, representam 100\% do território nacional.

A opção pelo questionário deu-se pela facilidade de processar a coleta de dados junto às empresas selecionadas que se encontram dispersas geograficamente.

A idéia era levantar a situação atual das referidas empresas quanto à gestão da informação, considerando aspectos 
como infra-estrutura tecnológica e utilização de tecnologias de informação e comunicação, e verificouse como estavam lidando com os processos de comunicação e com os aspectos de treinamento e de capacitação. O intuito era identificar possíveis dificuldades na área de atuação industrial relativas ao tipo de informação especializada, ou mesmo à falta de informação.

O perfil das empresas em questão foi delineado e, a partir dele, foi possível identificar ações de inclusão empresarial para propiciar melhorias na rede de representação comercial.

\section{CONTEXTUALIZAÇÃO DAS EMPRESAS}

A legislação especifica que a representação comercial autônoma é atividade regulamentada pela Lei no 4.886 de 9 de dezembro de 1965, podendo ser exercida por pessoa física ou jurídica (art. 1ำ e parágrafo único), sendo obrigatório o seu registro no Conselho Regional (art. $2^{\mathrm{o}}$ ), com alterações introduzidas pelas Leis de números 65.705, de 14 de novembro de 1969, 6.994, de 26 de maio de 1982, e 8.420, de 08 de maio de 1992, e introduz alterações na Lei ${ }^{\circ}$ 4.886, de 9 de dezembro de 1965, que regula as atividades dos representantes comerciais autônomos (SAAD, 1998).

Observa-se que a indústria passa a ser repensada para acompanhar as transformações desta "nova ordem mundial”, assim como o modelo corporativo tradicional das empresas. E, então, começam a surgir alternativas diferentes para garantir boas relações comerciais e ganho de competitividade.

Foi-se o tempo em que as empresas de representação se restringiam à área comercial com foco exclusivo para as vendas. Atualmente, tais empresas se tornaram potenciais fontes geradoras de negócios e têm se apresentado como alternativa para alavancagem de negócios das grandes empresas.

\section{GESTÃO DA INFORMAÇÃO PARA A TOMADA DE DECISÃO}

Este é um momento em que as empresas públicas e privadas, os governos estaduais e o federal, além da sociedade civil, passaram a repensar um novo projeto para o país direcionado para ações de inserção social, digital e empresarial, propiciando, assim, condições para competir em um mundo econômico, político, social e culturalmente globalizado que se estrutura no saber.
A grande mudança na sociedade contemporânea é que a informação se tornou insumo essencial para a sobrevivência de qualquer organização, e, torna-se indispensável, portanto, que os gerentes e altos administradores disponham de informação confiável, adequada, em tempo certo, para que o processo decisório seja eficaz e eficiente.

Para Galvão (1999), a sociedade da informação se afirma em uma economia da informação na qual:

parte significativa do valor econômico repousa [...] nos grandes fluxos de informações [...] proporcionados pela ligação dos microcircuitos com as redes de telecomunicações com capacidades de tráfego crescente.

Moresi (2001) corrobora que, nas organizações, o fluxo da informação se torna um processo para agregar valor, e o sistema de informação passa a ser considerado como a sua cadeia de valor, por ser, de fato, o suporte utilizado para a produção e a transferência da informação.

Tarapanoff (2001) alinhava as características da sociedade da informação:

A informação constitui a principal matéria-prima [...] o conhecimento é utilizado na agregação de valor a produtos e serviços, a tecnologia constitui elemento vital para as mudanças [...], a rapidez, a efetividade e a qualidade constituem fatores decisivos de competitividade.

Indiscutível dizer que o conceito de gestão da informação evoluiu de forma considerável e passou a ser uma atividade estratégica planejada em função da melhoria do desempenho e da produtividade organizacional.

Conforme Tarapanoff (2001), o objetivo da gestão da informação é

identificar e potencializar os recursos informacionais de uma organização e sua capacidade de informação, ensiná-la a aprender e a adaptar-se às mudanças ambientais.

No ambiente competitivo, é requerida a redução de tempo entre o registro e a disponibilização de informações voltadas para processos de tomada de decisão. Em virtude disso, o gerenciamento de informações nos processos organizacionais deve permear toda a cadeia de valores do ciclo informacional, ressaltando a maximização de valor do uso da informação, a minimização dos custos de aquisição, o processamento e a utilização da mesma, a delegação de responsabilidades para o seu uso efetivo, eficiente e 
econômico, além da confiança no trâmite informacional (DAVENPORT, 2001; CIANCONI, 1999).

Apesar da constante preocupação com a tecnologia da informação, o gerenciamento das informações propriamente dito tem sido com freqüência relegado ao segundo plano, em razão do enfoque exclusivo na tecnologia, e não nos conteúdos informacionais. Especificamente, nas pequenas e médias empresas, este problema pode ser resultante da falta de recursos financeiros, de pessoal especializado, ou mesmo do desconhecimento das fontes de informação acessíveis. Somando-se a estes fatores, a preocupação com a atividade-fim.

Segundo Cianconi (1999), as tecnologias da informação constituem o instrumental necessário, enquanto as normas e metodologias compõem a infra-estrutura para que ocorra o gerenciamento da informação.

\section{INCLUSÃO DIGITAL E INCLUSÃO EMPRESARIAL}

A utilização das novas tecnologias da informação e comunicação e, em especial da Internet, provocou mudanças radicais na forma de trabalhar, trocar, acessar informações e relacionar-se com o resto do mundo.

A principal característica dos tempos atuais seria o crescimento da quantidade de informações a serem processadas por uma organização. Nesse aspecto, Cianconi (1999) é assertiva:

Apesar da superprodução de informações propiciada pela tecnologia, é escassa a informação relevante, correta, organizada de forma a se tornar útil - o que leva à necessidade de efetuar cuidadoso projeto e planejamento da coleta e disseminação, voltada às reais necessidades dos usuários e clientes, não a partir do ponto de vista de quem desenvolve ou coleta as informações para alimentar o sistema.

Empresas passam a ter como estratégia a formação de redes, adotando um sistema de flexibilidade organizacional, pois precisam se tornar cada vez mais efetivas. $\mathrm{O}$ foco de atenção deve estar voltado para a capacidade da empresa de gerar e utilizar sistemas integrados de informação, disseminados em redes, para subsidiar o processo de crescimento organizacional. Torna-se, portanto, visível que a competitividade das organizações passa a estar relacionada à abrangência das redes em que estão inseridas e à intensidade do uso que fazem das mesmas (BAPTISTA, 1997, apud LASTRES, 1999).
O fenômeno chamado "inclusão digital" tem criado desigualdades no uso das tecnologias da informação e comunicação, devendo, estas, portanto, serem compartilhadas; caso contrário, corre-se o risco da ampliação da nova casta de "excluídos digitais". Ressaltase que a inclusão digital não se restringe a ensinar a utilizar a tecnologia ou a disponibilizar o acesso à rede. É preciso um trabalho de identificação das demandas informacionais. Além disso, a produção de conteúdos deve ser vista como uma estratégia importante no processo de inclusão, somando-se aos demais esforços, como formação e capacitação de multiplicadores, criação de redes locais e comunidades virtuais, integração com políticas públicas e ações de responsabilidade social. Destaca-se que o tripé da inclusão digital compreende o seguinte: renda, novas tecnologias da informação e comunicação e acesso à educação.

Para Suaiden (2003), a inclusão digital se faz de bom termo quando se tem o que ele denomina

"mediadores da informação", que primeiro trabalham o conceito de "alfabetização da informação", para que se possa utilizar o computador, acessar a Internet e retirar informações, conceitos e conteúdos que empreendam melhoria no processo de ensinoaprendizagem. [...] estar incluído digitalmente significa saber selecionar e analisar o que se tem e com o que se pretende trabalhar.

Quando se aborda a questão da inclusão digital, pensa-se exclusivamente naqueles desprovidos de recursos tecnológicos; no entanto ficam à parte os empresários e funcionários que não possuem o "acesso seletivo" ao conhecimento abundante e disponível gratuitamente (ou quase) na Internet e em outras mídias (SOFTWARE, 2003).

Em seu site, a Câmara Brasileira de Comércio Eletrônico define inclusão empresarial como "a criação de programas que permitam a disseminação da Internet nas empresas, tendo como alvo as pequenas e as médias empresas". Aparentemente, seria uma visão restrita à tecnologia; contudo, mais adiante, expõe que, com a Internet, além dos ganhos de produtividade que podem ser conquistados, o fator principal seria a ampliação dos horizontes de mercado destas empresas, incentivando o que se denomina concorrência assimétrica, isto é, a possibilidade que uma empresa de menor porte e com menos capilaridade poderia ter de concorrer com competidores maiores. 
Atualmente, o fato de "somente estar ligado" aos recursos tecnológicos que disponibilizam a grande massa de informação não mais adianta. Urge que os empresários saibam ser seletivos no processo informacional de suas empresas para que não sejam coadjuvantes nos acontecimentos que os afetam direta e indiretamente. Ora, cabe então fazer com que a inclusão empresarial possibilite a geração de inteligência empresarial mediante as tecnologias da informação e comunicação existentes e as que ainda estão por vir.

\section{GESTÃO EMPRESARIAL NA SOCIEDADE DO CONHECIMENTO}

Lastres (1999) destaca o novo padrão em que

a informação e o conhecimento passaram a se constituir nos recursos básicos do crescimento econômico e que tais recursos não são esgotáveis. Além disso, o consumo dos mesmos não os destrói, e seu descarte geralmente não deixa vestígios físicos.

As empresas são os primeiros entes afetados pelas transformações mundiais advindas da acirrada competitividade dos mercados, portanto há necessidade de disponibilizar informações para o setor produtivo, no sentido de atender de forma ampla à demanda. $\mathrm{Na}$ verdade, as organizações devem reformular suas estruturas, encontrar formas gerenciais de estimular novas práticas, valorizar a criatividade e o compartilhamento de idéias e reaprender com seus colaboradores, parceiros e clientes.

Nonaka e Takeuchi (1997), em citação de Lastres (1999), destacam que o modelo baseado nas tecnologias da informação e comunicação aponta para a complexidade de novos processos produtivos, implicando mudanças mais rápidas com relação aos processos, bens e serviços. Com isso, haverá necessidade de capacitação e de recapacitação para que indivíduos e instituições se mantenham atualizados de forma contínua.

O investimento na capacitação e na atualização de funcionários passa a ser visto como uma forma de agregar valor à organização e de formar o capital humano que vai transformar o conhecimento produzido dentro e fora da empresa em conhecimento produtivo e competitivo, contribuindo, então, para transformá-la em uma organização voltada para o aprendizado e para o conhecimento (LASTRES, 1999).
Cassiolato (1997), citada por Lastres (1999), destaca que

as mudanças atuais contribuem para a transformação da economia no sentido de colocar o conhecimento como o recurso mais estratégico e o aprendizado como o processo mais importante.

\section{A gestão do conhecimento}

é um processo que envolve criar, colher, assimilar e aproveitar o conhecimento, de modo a gerar uma empresa mais inteligente e competitiva. E o que se gerencia é esse processo (BERG, 1998).

No momento atual, as organizações estão agregando valor aos próprios produtos mediante a aplicação da inteligência de seus colaboradores. Por isso, observa-se o crescente investimento no capital intelectual. Para Stewart (1998), o capital intelectual pode ser entendido como a soma de todos os ativos de conhecimento de uma organização.

Conforme Ludwig, citada por Rezende (2002), "gerenciar o capital intelectual é tarefa complexa, porque inclui a gestão do conhecimento e a gestão da informação [...]".

Uma das melhores formas para valorizar o potencial intelectual das organizações é compreender onde se encontram as competências. Desta forma, é possível estruturar programas de aprendizagem e de educação corporativa destinados à evolução desses ativos de conhecimento que realmente agregam valor para a empresa.

Os sistemas automatizados podem trazer a fonte de informação para o cliente, de forma virtual e instantânea, visto que o ganho no fator tempo é fundamental. Os novos meios de comunicação e as tecnologias emergentes são realmente necessários para atender à demanda das organizações de alta performance.

\section{EDUCAÇÃO CORPORATIVA E E-LEARNING}

Nas organizações, a gestão do conhecimento pode ser considerada como o esforço para melhorar o desempenho humano e educacional. Isso significa garantir que todos dentro da organização tenham acesso ao conhecimento, quando, onde e na forma que melhor convier, além de ajudar e motivar os detentores de conhecimento [...] a codificarem parte de seu conhecimento e colaborarem com outros (TERRA; GORDON, 2002). 
De acordo com o Decreto 2.494, de 10.02.1998 do MEC,

Educação à Distância é uma forma de ensino que possibilita a auto-aprendizagem, com a mediação de recursos didáticos sistematicamente organizados, apresentados em diferentes suportes de informação, utilizados isoladamente ou combinados, e veiculados pelos diversos meios de comunicação.

A educação corporativa visa a estruturar o aprendizado para a realidade específica de uma organização, diagnosticar as necessidades de novos conhecimentos e buscar soluções de educação e treinamento, integrando a aprendizagem aos programas da instituição de modo a obter os melhores resultados. A educação corporativa vem se utilizando dos aparatos da EAD e da virtualidade proporcionada pelo e-learning (NISKIER; BLOIS, 2003).

Para Terra e Gordon (2002), o portal de conhecimento corporativo é uma ferramenta tecnológica essencial ao processo de ensino e aprendizagem da atualidade, uma vez que é caracterizada pela unificação das aplicações, informações e serviços, personalização e atualização constante no processo de disponibilizar informações. O sucesso do portal de conhecimento corporativo está diretamente relacionado com a sua utilização diária para o desenvolvimento de atividades profissionais, devendo, portanto, transformar-se em uma solução desktop.

No Brasil, as organizações começam a disponibilizar, em portais corporativos, iniciativas educacionais como as universidades do conhecimento corporativo, que são soluções de educação a distância voltadas à aprendizagem continuada para o desenvolvimento do capital intelectual das organizações e que situam, na Internet, todas as suas instalações educativas. A principal função da universidade corporativa é viabilizar a gestão do conhecimento nas empresas para torná-las mais aptas a competir.

Oe-learning caracteriza-se pelo uso de novas tecnologias multimídias e da Internet para melhorar a qualidade da aprendizagem mediante o acesso a recursos e serviços, além das colaborações e intercâmbios a distância.

A tendência tem sido de experiências híbridas, nas quais se reúnem o auto-aprendizado, o gerenciamento de conhecimento e o e-learning para o direcionamento das necessidades de aprendizado dos diferentes tipos de usuários. O ideal é que haja um mix de aulas convencionais e virtuais. E é neste sentido que as universidades corportivas devem concentrar seus esforços.

\section{PROCEDIMENTOS METODOLÓGICOS}

Inicialmente, foi realizada uma análise de literatura visando a identificar e analisar documentos relativos a estudos desenvolvidos sobre as experiências brasileiras com empresas de representação comercial na área da indústria, nas áreas de informação e comunicação, automação e capacitação para visualizar movimentos de inclusão empresarial.

Com base na literatura, observou-se que praticamente inexistem informações sobre o foco deste estudo quanto às empresas de representação comercial, principalmente, sobre o segmento industrial. Foram levantados artigos sobre as áreas correlatas e dados estatísticos sobre pequenas e médias empresas no mercado nacional. Quatro pressupostos serviram como norteadores para a realização da pesquisa: as empresas estudadas precisam de apoio e recursos para atingir a inclusão digital; não formam redes para o compartilhamento de informações; apresentam carências na gestão da informação; as necessidades de informação devem ser contempladas pelos serviços de informação das representadas.

Procurou-se identificar empresas de representação comercial em diversas capitais do país que atuam no mesmo segmento técnico-industrial. Optou-se pelo segmento de suprimentos industriais, chegando-se, especificamente, aos produtos técnicos de borracha. A amostra contemplou 17 empresas localizadas em SP, RJ, MG, RS, PR, BA, SC, PE, ES, CE, PA, MT, RO e TO, interligadas por representarem uma empresa multinacional norte-americana em comum. A maior parte destas empresas é responsável por mais de um estado; juntas, representam $100 \%$ do território nacional.

Para a realização da pesquisa, o instrumento utilizado foi o questionário com 40 (quarenta) questões fechadas, abertas e de múltipla escolha. A opção pelo questionário deu-se pela facilidade de processar a coleta de dados junto às empresas selecionadas que se encontram em diversos estados do país.

O estudo tem como objetivo proporcionar uma visão geral acerca do perfil das referidas empresas no que tange às áreas de informação e comunicação.

Foi feito um roteiro para o questionário, contemplando temas que estariam de acordo com os objetivos do estudo. O referido roteiro foi organizado e, a partir dele, foram formuladas as questões. Estas foram divididas nos seguintes grupos: Sua Empresa; Funcionários; 
Capacitação e Treinamento; Equipamentos e Softwares; Sua Empresa e as Empresas Representadas; Comunicação e Informação na Sua Empresa. Foi aplicado o pré-teste, e, posteriormente, realizou-se o envio dos questionários via correio eletrônico e via correio tradicional, ocorrendo a devolução de 14 respondidos, totalizando $82,35 \%$.

\section{RESULTADOS E CONCLUSÕES}

Buscou-se delinear o perfil das empresas, identificando a situação das mesmas no tocante à infra-estrutura e aos aspectos de tecnologias de informação e comunicação, de treinamento e capacitação, verificando como tais organizações lidam com a gestão da informação e os processos de comunicação. Procurou-se, também, relacionar alternativas viáveis de uso das tecnologias de informação e comunicação para o processo de aprendizado e inovação nas empresas envolvidas. E, finalmente, foram identificadas ações de inclusão empresarial para propiciar a capacitação corporativa e a participação social.

As empresas estudadas são de pequeno ou médio porte, com exceção de uma que pode ser considerada como outlier na amostra. A referida empresa já está consolidada no mercado há 20 anos com atuação em diversos segmentos. Apesar das variáveis externas (impostos, taxações, encargos etc.), a maioria das empresas apresenta seus recursos otimizados, contando com boa quantidade de equipamentos e bom nível funcional.

Os resultados do estudo foram surpreendentes, pois pensava-se na necessidade de apoio e de recursos para o processo de inclusão digital, e não se concebia que a mesma já estivesse configurada nesse ambiente. A inclusão digital é uma realidade nas referidas empresas, pelo menos nos aspectos recursos e tecnologia. $O$ último aspecto que sustenta a inclusão digital é o "conteúdo", e este item é o que deve ser trabalhado por tais empresas.

É fundamental definir os processos para a seleção dos conteúdos para que, depois, sejam tratados e transformados em serviços (consultoria) ou produtos (treinamento). Em seguida, deve-se rever o plano de ação da empresa e verificar quais informações podem subsidiálo. Depois, analisar que tipo de conhecimento técnico deve ser adquirido pelos integrantes da empresa para o desenvolvimento organizacional.

Outro aspecto abordado no estudo trata da rede para o compartilhamento de informações, e, de fato, não existe iniciativa nesse sentido. Inicialmente, a sugestão seria que os empresários se mobilizassem para criar uma lista de distribuição de correio eletrônico para trocar idéias, formular perguntas e difundir informações, pois se baseia em sistema de subscrição voluntária e aborda temáticas específicas. Esse recurso é uma prática gratuita do correio eletrônico.

A proposta seria que as empresas de representação firmassem parcerias com as representadas para o desenvolvimento de um portal corporativo, com vistas à consolidação da rede.

Quanto aos conteúdos, é preciso estabelecer fluxos de informações estratégicas, tecnológicas, mercadológicas, comerciais e inclusive sociais, elencar links de interesse do setor e relacionar fontes de informação especializada, de modo que as empresas possam ganhar tempo no acesso às informações e, mais do que isso, que se obtenha um desenvolvimento integrado dos atores envolvidos.

Em razão do porte das empresas representadas, torna-se mais fácil fazer alianças com entidades do segmento, como, por exemplo, com a Confederação Nacional da Indústria, o Ministério do Desenvolvimento, Indústria e Comércio Exterior, entre outros.

O estudo trata da gestão da informação, e foram detectadas as principais dificuldades quanto ao tratamento da mesma nas etapas de coleta, seleção, análise e organização.

Conforme Cianconi (1999), o êxito do processo de gestão da informação está relacionado com as respostas de algumas questões como: Quais são as informações relevantes possuídas pela sua empresa? Quem as possui e quem são os gestores dessas informações? Quais são as suas fontes de informação? Como são organizadas, controladas, armazenadas? Como são compartilhadas? Quais são as informações necessárias? Como obtê-las? Há um executivo de alto nível que defenda a informação na sua empresa?

Essencialmente, o caminho seria o mapeamento de informações, identificando os tipos necessários, partindo, então, para a categorização. Depois, torná-las disponíveis para o acesso, observando-se questões, como, por exemplo, sigilo e segurança. E, finalmente, partir para a elaboração de um planejamento que contemple o que vai ser coletado e disseminado, para quem e como.

Outro ponto tratado se refere às reais necessidades de informação e conhecimento das empresas de 
representação que devem ser atendidas pelos serviços de informação das empresas representadas, em função do vínculo corporativo existente.

Todos os empresários disseram utilizar os sites e portais de suas empresas representadas com o intuito de buscar informação, cadastrar e acompanhar pedido, fazer consulta técnica, mostrar os sites para os clientes, além de verificar estoque, preço e prazo. Aparentemente, conseguem atender a suas necessidades de informação, sobretudo, para questões operacionais. Entretanto, foi possível detectar questões que poderiam ser mais adequadas junto às representadas, como mais informações sobre as políticas institucionais e as estratégias regionais, visitas mais freqüentes, um canal exclusivo de comunicação, respostas mais rápidas, informativos periódicos, um sistema gerencial de informação e comunicação adequado à atividade-fim, melhoria da interação e obtenção de informações de grandes grupos para firmar parcerias com as empresas de representação.

\section{CONSIDERAÇÕES FINAIS}

O estudo sugere a promoção da inclusão empresarial de organizações que compõem redes (físicas) de representação comercial do segmento, destacando que a forte tendência das organizações da era do conhecimento é empreender esforços para a criação e (ou) participação de portais e universidades do conhecimento corporativo visando a um estratégico diferencial competitivo.

Novas ações e melhores relações entre representantes, clientes e empresas representadas podem ser desenvolvidas mediante a criação de um portal do conhecimento corporativo.

Para potencializar ações de inclusão empresarial, a proposta seria complementada por projeto de implantação de uma universidade do conhecimento corporativo que possa oferecer, inicialmente, treinamentos para clientes, recapacitação para funcionários e atualização para empresários, com programas educativos e cursos técnicos, viabilizando, inclusive, a formação de redes integradas.

Em um segundo momento, a referida universidade poderia expandir sua atuação junto às faculdades de engenharia, aos centros técnicos do país e às associações empresariais, gerando capilaridade na área de informaçãoconhecimento-educação.
Nesse contexto da universidade do conhecimento corporativo, caberia, ainda, o desenvolvimento de um programa de responsabilidade social voltado para a inclusão digital de familiares dos funcionários das empresas envolvidas.

Trata-se, portanto, da consolidação do processo de capacitação em redes virtuais de empresas desse segmento, como geradoras potenciais de negócios e de desenvolvimento auto-sustentado.

Artigo submetido em 14/06/2006 e aceito em 10/07/2006.

\section{REFERÊNCIAS}

ANDRADE, Sonia Cruz-Riascos de. A Inclusão digital nas empresas de base industrial: a utilização de tecnologias da informação e comunicação. 2004. 85 f. Monografia (Especialização em Inteligência Organizacional e Competitiva na Sociedade da Informação) - Departamento de Ciência da Informação e Documentação, Universidade de Brasília, Brasília, 2004

BERG, Thomas. A empresa bem-sucedida do século 21: a chave é a tecnologia. Exame, São Paulo, v. 32, n. 18, p. 82-84, ago. 1998.

BRASIL. Ministério da Educação. Disponível em: < $\underline{\text { http:// }}$ www.mec.gov.br/Sesu/educdist.shtm/>. Acesso em: 2006.

CÂMARA BRASILEIRA DE COMÉRCIO ELETRÔNICO. Disponível em: <http://www.camara-e.net/>. Acesso em: 2006.

CASSARRO, Antônio Carlos. Sistemas de informação para tomada de decisões. São Paulo: Pioneira, 1994.

CASTELS, Manuel. A sociedade em rede. São Paulo: Paz e Terra, 1999. v.1. p.171-217.

CAVAlCANTI, Marcos; GOMES, Elisabeth; PEREIRA, André. Gestão de empresas na sociedade do conhecimento: um roteiro para a ação. Rio de Janeiro: Campus, 2001. 170 p.

CIANCONI, Regina. Gestão da informação. Brasília: SENAI, 1999.

CIDADANIA corporativa: estratégias bem-sucedidas para empresas responsáveis. Rio de Janeiro: Qualitymark, 2001. p. 291-303.

DAVENPORT, Thomas H. Ecologia da Informação. São Paulo: Futura, 2001.

GALVAO, Alexander Patêz. A informação como commodity: mensurando o setor de informações em uma nova economia. Ciência da Informação, v. 28, n. 1, jan. 1999. [Citado 02 Setembro 2003], p.67-71. Disponível em: <http://www.scielo.br/scielo.php?script=sci arttext\& $\mathrm{pid}=\mathrm{S} 010019651999000100009 \& \operatorname{lng}=\mathrm{pt} \& \mathrm{nrm}=\mathrm{iso}>$. Acesso em: 2006.

GONZALEZ, Marco; POHLMANN Foo, Omer; BORGES, Karen Selbach. Informação digital no ensino presencial e no ensino a distância. Ciência da Informação, Brasília, v. 30, n. 2, maio/ago. 2001.

INSTITUTO BRASILEIRO DE GEOGRAFIA E ESTATÍSTICA IBGE. Disponível em: <http://www.ibge.gov.br/home/presidencia/ noticias/26082002 cadastroempresa.shtm >. Acesso em: 2006.

$\mathrm{KOCH}$, Walter. Arquitetura dos sistemas. Mundo da Imagem, CENADEN, n. 25, jan./fev.1998.

LAKATOS, Eva Maria. Metodologia do trabalho científico: procedimentos básicos, pesquisa bibliográfica, projeto e relatório, publicações e trabalhos científicos. São Paulo: Atlas, 2001. 


\section{Processo de inclusão digital em rede empresarial do segmento de suprimentos industriais: utilização de tecnologias de informação e comunicação}

LASTRES, Helena M. M. Informação e conhecimento na nova ordem mundial. Ciência da Informação, v. 28, n. 1, jan. 1999. [Citado 10 Fevereiro 2004], p.72-78. Disponível em: <http://www.scielo.br/ scielo.ph p s c ript $=$ sci_art text \& pid = S 0100 $19651999000100010 \& \operatorname{lng}=\mathrm{pt} \& \mathrm{nrm}=$ iso $>$. Acesso em: 2006.

MACMORROW, Noreen. Knowledge management: an introduction. Annual Review of Information Science and Technoloy, v. 35, p. 381-422, 2001.

MIRANDA, Antonio. Ciência da informação: teoria e metodologia de uma área em expansão. Brasília: Thesaurus, 2003.

MORESI, Eduardo Amadeu Dutra. Gestão da informação e do conhecimento. In: TARAPANOFF, Kira (Org.). Inteligência organizacional e competitiva. Brasília: Ed. UnB, 2001. p. 111-142.

MORIN, Edgar. Da necessidade de um pensamento complexo. In: PARA navegar no século XXI, tecnologias do imaginário e cibercultura. Porto Alegre: Sulina, 2000.

NISKIER, Celso; BLOIS, Marlene. A UNIVIR: três anos consolidando o e-learning nas empresas. In: EAD.BR: experiências inovadoras em educação à distância no Brasil: reflexões atuais, em tempo real. São Paulo: Anhembi Morumbi, 2003. p.111-123.
OLIVEIRA, Cecília Leite. A Revolução tecnológica e a dimensão humana da informação: a construção de um modelo de mediação. 2003. 205 f. Tese (Doutorado em Ciência da Informação)Departamento de Ciência da Informação e Documentação, Universidade de Brasília, Brasília, 2003.

REZENDE, Iara. Informação para negócios: os novos agentes do conhecimento e a gestão do capital intelectual. Ciência da Informação, v. 31, n. 1, 2002.

SAAD, Ricardo Nacim. Representação comercial: comentários à Lei n. 4886/65, com alterações da Lei n. 8.420, de 8 de maio de 1992. São Paulo: Saraiva, 1998.

SOFTWARE livre e inclusão digital. São Paulo: Conrad, 2003.

STEWART, Thomas A. Capital intelectual: a nova vantagem competitiva das empresas. Rio de janeiro: Campus, 1998.

SUAIDEN, Emir. Inclusão digital em debate na UnB. Brasília: [s.n.], nov. 2003.

TARAPANOFF, Kira. O contexto da mudança. In: Inteligência organizacional e competitiva. Brasília: Ed. UnB, 2001. p. 51-58.

TERRA, J. C.; GORDON, C. Portais corporativos: a revolução na gestão do conhecimento. São Paulo: Negócio, 2002. 